\title{
MORFOLOGIA DA UNIDADE DE DISPERSÃO E GERMINAÇÃO DE CORDIA SELLOWIANA CHAM. E CORDIA MYXA L. $\left({ }^{1}\right)$
}

\author{
ISABEL CRISTINA ERCOLINI BARROSO $(2 *, 5)$; FERNANDO DE OLIVEIRA $(2,3)$; \\ DEBORAH MARIA CIARELLI $\left({ }^{4}\right)$
}

\begin{abstract}
RESUMO
As unidades de dispersão das espécies Cordia sellowiana Cham. e Cordia myxa L. (Boraginaceae Jussieu) foram estudadas com ênfase em sua morfologia e no processo de germinação. Os frutos de Cordia sellowiana e de Cordia myxa são do tipo drupóide nuculânio. A protrusão da raiz primária, na primeira espécie, ocorre através de fenda longitudinal do pirênio, e na segunda, através de abertura do opérculo. A germinação, nas duas espécies, é do tipo fanerocotiledonar epígea. As plântulas apresentam cotilédones plicados.
\end{abstract}

Palavras-chave: pirênio, germinação, plântula.

\section{ABSTRACT \\ MORPHOLOGY OF THE DISPERSION UNIT AND GERMINATION OF CORDIA SELLOWIANA CHAM. AND CORDIA MYXA L.}

Cordia sellowiana Cham. and Cordia myxa L. (Boraginaceae Jussieu) had their dispersion units studied, with emphasis on their morphology and seed germination process. The fruits from both Cordia sellowiana and Cordia myxa are of the drupoid nuculanium type. The protrusion of the primary root in the former species occurs through a pyrene longitudinal fissure; in the latter it is one through an opening in the operculum. In both species, seed germination is of the epigel phanerocotylar type. The seedlings have plicate cotyledons.

Key words: germination, pyrene, seedling.

$\left({ }^{1}\right)$ Parte de dissertação de mestrado da primeira autora. UNESP - Rio Claro, Área de Biologia Vegetal. Recebido para publicação em 21 de maio de 2007 e aceito em 9 de setembro de 2008.

$\left({ }^{2}\right)$ Fundação Municipal de Ensino Superior (FESB) - Bragança Paulista. E-mail:belbarroso@hotmail.com. $\left(^{*}\right)$ Autora correspondente. Alameda Holanda ,182, 12919-150 Bragança Paulista (SP). Bolsista do CNPq.

$\left({ }^{3}\right)$ Universidade de São Paulo - Faculdade de Ciências Farmacêuticas. E-mail: olifern@uol.com.br

$\left({ }^{4}\right)$ Companhia de Saneamento Básico do Estado de São Paulo (Sabesp), Rod. Fernão Dias, km 8 - Vargem (SP).

$\left({ }^{5}\right)$ Doutoranda do curso de Pós-graduação em Biologia Vegetal - Unicamp. 


\section{INTRODUÇÃO}

Uma característica ecológica presente em Boraginaceae Jussieu é a capacidade de muitas de suas espécies de se estabelecerem em áreas bastante perturbadas. É comum encontrar representantes de Cordia ocupando áreas próximas a rodovias, onde é possível observar processo de degradação. São, portanto, espécies úteis para o reflorestamento de áreas onde a ação antrópica é evidente.

Segundo LORENZI (1992), Cordia sellowiana pode ser utilizada em plantios ornamentais e mistos destinados à recomposição de áreas degradadas. É uma planta pioneira, sendo seus frutos consumidos pela fauna. ERCOLINI BARroso (2002) citou o emprego de Cordia myxa, para a produção de madeira e medicinal.

Estudos sobre estrutura de frutos, sementes e plântulas de Boraginaceae são escassos. Autores como Duke e Pohill (1981) asseveram que em conjunto sementes e plântulas podem revelar muito sobre a história ecológica e evolutiva das plantas. Além disso, a utilização de características das sementes e dos frutos com finalidade taxonômica é de grande utilidade na identificação de famílias, de gêneros e de espécies, visto que são pouco alteráveis diante das variações ambientais (Murley 1945, Boelke 1946, Bravato 1974, Palacios e Bravo 1975, Beltrati 1978 e RicARDi et al. 1987). Exemplo dessa aplicação é dada por BARROSO et al. (1999), que utilizam várias características de frutos e de sementes na identificação de famílias e gêneros de dicotiledôneas.

A compreensão da dinâmica dos ecossistemas naturais e o estabelecimento de metodologias adequadas à recuperação de áreas degradadas, necessita do reconhecimento das espécies em suas etapas iniciais de desenvolvimento. Oliveira (1993) destaca que pouco se conhece sobre as plântulas das espécies nativas, em geral.

Consequentemente, a realização de estudos sobre elas é importante para o plano de atividade estabelecido pela Política Nacional de Plantas Medicinais e Fitoterápicos do Brasil (CORREA et al. 2006). Essa política visa fomentar o desenvolvimento de pesquisas que levem à expansão do cultivo de plantas medicinais protegendo a biodiversidade brasileira e, segundo BRANDÃo et al. (2006), considerando a validação do uso de espécies autóctones e introduzidas.

A existência de poucas informações referentes aos caracteres morfológicos de frutos, sementes e plântulas de Cordia faz com que a realização de trabalhos sobre esse grupo de plantas seja essencial no sentido de possibilitar investigações sobre sucessão e regeneração.
Este trabalho visa descrever características morfológicas de frutos, sementes e o desenvolvimento das plântulas das espécies C. selowiana e C. myxa.

\section{MATERIAL E MÉTODOS}

As populações de C. sellowiana e de C. myxa utilizadas como fornecedoras de material empregado na realização do estudo tiveram as seguintes origens: C. sellowiana Brasil, São Paulo, Município de Vargem, sítio Kadu, em altitude entre 800 e 900 m, 22 ${ }^{\circ} 55^{\prime} \mathrm{S}$ e $46^{\circ} 24^{\prime}$ W. Brasil, São Paulo, Município de Rio Claro, Campus da UNESP em altitude de aproximadamente $650 \mathrm{~m}$ a $22^{\circ} 22^{\prime} \mathrm{S}$ e $47^{\circ} 28^{\prime} \mathrm{W}$. Exsicatas referência de estudo (HRCB 32789), (HRCB 11280), (HRCB 28085), (HRCB 28086), (HRCB 15323). C. myxa - Brasil, São Paulo, Município de Rio Claro, Campus da UNESP em altitude de aproximadamente $650 \mathrm{~m}$ a $22^{\circ} 22^{\prime} \mathrm{S}$ e $47^{\circ} 28^{\prime} \mathrm{W}$. Exsicatas referência de estudo (HRCB 5829), (HRCB 6460), (HRCB 6016).

Os frutos de ambas as espécies foram coletados quando desenvolvidos e maduros, sendo considerados como maduros os frutos de cor amarelada a alaranjada, acondicionados em saco de papel, transportados para o laboratório, sendo despolpados manualmente.

As características morfológicas dos frutos foram analisadas em 50 unidades de material fresco. As amostras foram provenientes de seis indivíduos de cada espécie e as descrições dos tipos de frutos foram baseadas nos trabalhos de Spujt (1994) e BARroso et al. (1999). Para determinar o diâmetro foi utilizado um paquímetro e para a massa uma balança analítica. Para cada conjunto de dados foram calculados média, desvio-padrão e a amplitude de variação.

A morfologia dos frutos foi analisada com o auxílio de lupa. Para os aspectos das plântulas foram utilizadas quatro repetições de 50 sementes, ainda no interior do pirênio das espécies. Um lote de cada espécie foi distribuído em caixas do tipo gerbox, sobre duas folhas de papel de filtro umedecidas com $5 \mathrm{~mL}$ de água destilada, mantidas em germinador Fanen $347 \mathrm{G}$ a $25 \pm 1{ }^{\circ} \mathrm{C}$, sob iluminação fluorescente branca contínua. Outro lote foi mantido em escuro contínuo, colocando-se os pirênios em caixa gerbox preta. A contagem do número de sementes germinadas foi realizada a cada 24 horas. O critério para caracterizar a germinação foi a protrusão da raiz primária. No tratamento do escuro contínuo, a contagem foi feita sob luz verde de segurança. Sementes de dois lotes de cada uma das espécies foram colocadas para germinar, um em bandeja contendo Plantmax e outro em bandeja contendo vermiculita, sendo ambos mantidos em casa de vegetação. 
Após a emissão dos primeiros eófilos foram transplantadas para sacos plásticos de polietileno de $2 \mathrm{~kg}$ contendo uma mistura de terra e adubo orgânico (3:1) e mantidas em viveiro com sombrite $50 \%$. Tanto os pirênios colocados em germinador como os da casa de vegetação foram regados diariamente. Foram descritas e ilustradas as diferentes fases de desenvolvimento das plântulas.

Os termos plântula e planta jovem foram empregados para definir os estágios iniciais de desenvolvimento pós-seminal. Considerou-se como fase de plântula a que transcorre desde a emissão da raiz primária até a expansão dos primeiros eófilos e de planta jovem, a fase representada por qualquer das formas assumidas pelos vegetais até a expansão do primeiro metáfilo. A morfologia e os termos utilizados na descrição das plântulas estão de acordo com DUKE $(1965 ; 1969)$.

Para a germinação de C. myxa coletaram-se terra e 100 pirênios, em torno das árvores mães, os quais foram colocados para germinar em bandejas de isopor, em casa de vegetação. No período do experimento, as sementes foram regadas duas vezes por dia com microaspersor. Quando as plantas emitiram seus primeiros eófilos, foram transplantadas para sacos de polietileno de $2 \mathrm{~kg}$ segundo procedimento anteriormente descrito.

\section{RESULTADOS E DISCUSSÃO}

\section{Cordia sellowiana}

\section{Morfologia da unidade de dispersão}

Os frutos são providos de exocarpo membranáceo, mesocarpo suculento e mucilaginoso e endocarpo pétreo. Quando plenamente desenvolvidos, são elipsóides, ligeiramente assimétricos (Figura 1C) e com vestígios do estilete e estigma em pequena reentrância subapical, cuja posição, com o desenvolvimento do fruto, muda para localização quase equatorial. Quando maduros, a coloração varia do amarelo ao castanho e são glabros. Cálice persistente, aderido ao fruto durante todo o seu desenvolvimento, e com indumento pulverulento (Figuras 1A, B e C).

\section{Cordia sellowiana Cham.}
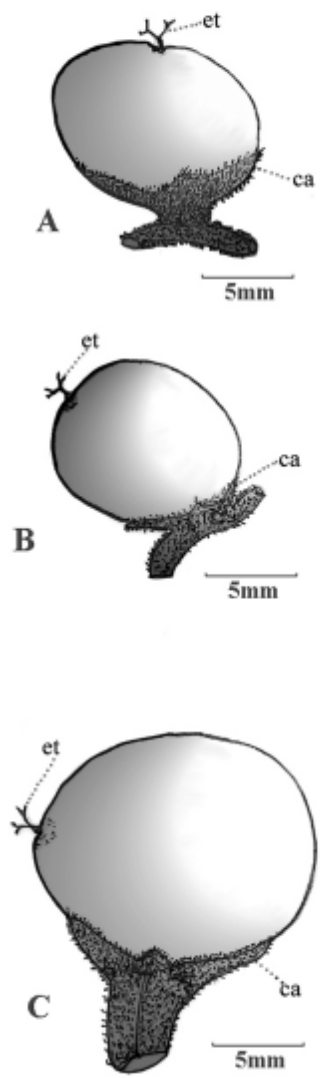
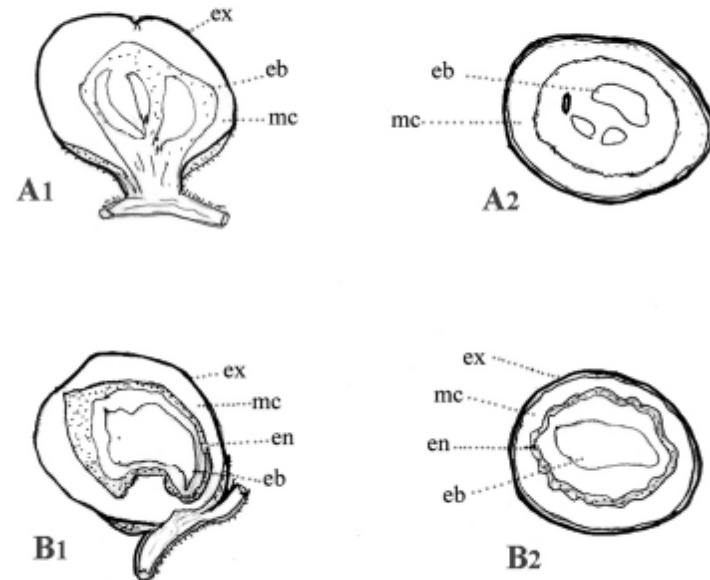

B2

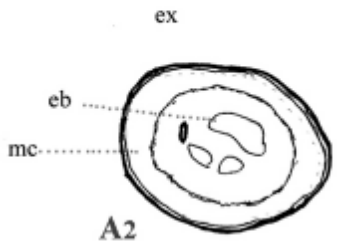

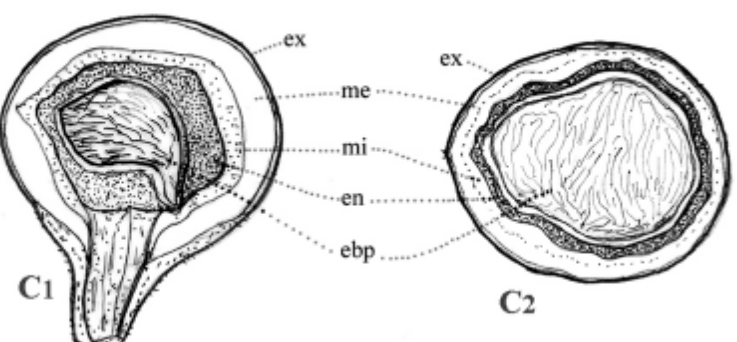

Figura 1. Cordia sellowiana Cham.: A, B e C: frutos inteiros; A1, B1 e C1: frutos cortados longitudinalmente; A2, B2 e $\mathrm{C} 2$ : frutos cortados transversalmente. ex = exocarpo; eb = embrião viável; $\mathrm{mc}=$ mesocarpo; em $=$ endocarpo; me $=$ mesocarpo externo; $\mathrm{mi}=$ mesocarpo interno; $\mathrm{ca}=$ cálice; et $=$ estígma; ebp = embrião com cotilédones. 
As figuras 1 A1, B1, C1 e 1 A2, B2, C2 correspondem, respectivamente, a corte longitudinal e transversal do fruto com indicação do exocarpo, mesocarpo e endocarpo.

Frutos jovens com quatro lóculos que, no final do desenvolvimento, se reduzem a um no interior do qual se desenvolve uma única semente. Pirênio arredondado, achatado em relação ao eixo longitudinal, com endocarpo aderido ao tegumento da semente, com rugosidade e duas projeções apicais (Figuras 2 A, B, C, D, E e F), uma delas mais evidente, constituindo o local por onde se inicia o rompimento do tegumento durante a germinação (Figuras 2 C, D e E). Na parte central, nota-se a presença de uma concavidade (Figura $2 \mathrm{~A}$ ), a cicatriz correspondente à inserção do pedúnculo.

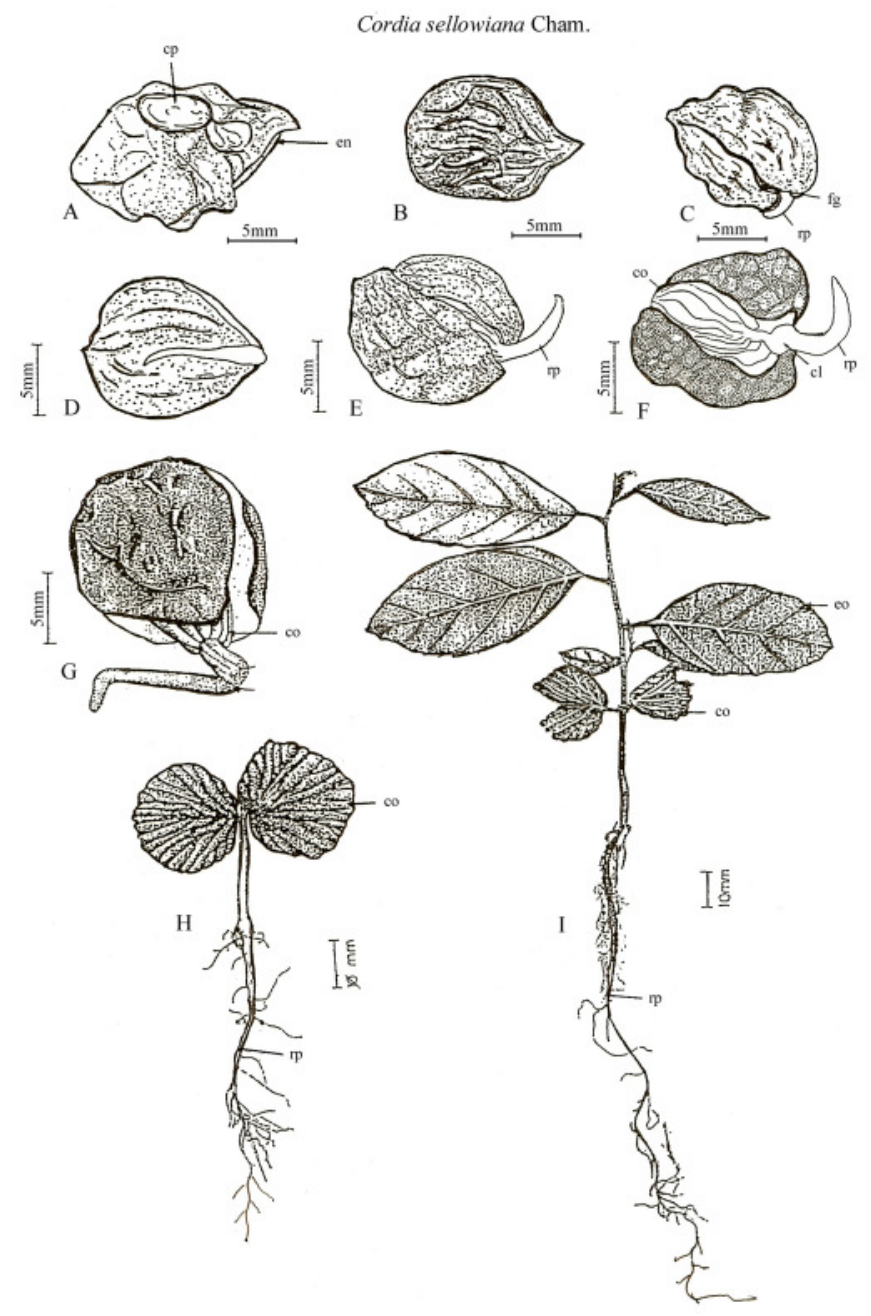

Figura 2. Cordia sellowiana Cham. $\mathrm{A}$ e $\mathrm{B}=$ pirênio em fase estacionária; C, D, E, F e G = pirênios com semente em germinação; $\mathrm{H}=$ plântula com 12 dias; $\mathrm{I}=$ planta jovem com 60 dias; $\mathrm{fg}=$ fenda de germinação; $\mathrm{cp}=$ concavidade; $c o=$ cotilédone $; \mathrm{cl}=$ coleto; $\mathrm{rp}=$ raiz primária; em = endocarpo pétreo; eo = eófilo.
A figura $1 \mathrm{C} 2$, corte transversal do fruto maduro mostrando o cotilédone plicado do embrião. Frutos de C. sellowiana maduros com diâmetro médio de 1,67 + 0,184 cm (média + desvio-padrão) variando entre $1,40 \mathrm{~cm}$ e $2,02 \mathrm{~cm}$. A massa fresca revelou média de 3,90 + 1,08 g (média + desvio-padrão com variação de 2,30 g a $6,27 \mathrm{~g}$ ).

A semente é constituída por tegumento pétreo, firmemente aderido ao endocarpo igualmente pétreo; contém embrião axial curvo provido de cotilédones foliáceos plicados e eixo hipocótilo-radícula curvo, menor que os cotilédones, envolto em endosperma.

\section{Aspectos da germinação}

O início da germinação ocorreu de 18 a 32 dias após a semeadura com emergência da raiz primária (Figura 2 C, D e E). A germinação é fanerocotiledonar epígea.

O pirênio possui um processo de intumescimento mais evidente em sua projeção apical maior onde, a seguir, se inicia o rompimento da parede longitudinalmente e a protrusão da raiz primária. Algumas vezes, nessa ocasião, fica mais evidente a presença de resíduos do mesocarpo mucilaginoso sobre a superfície do endocarpo rugoso, o qual assume coloração amarelo-hialina. Ao emergir do pirênio a raiz primária é branca e curva. A partir da saliência inicial, origina-se uma fenda longitudinal, que termina por expor a fase inicial da plântula, com região de coleto ligeiramente dilatada (Figura $2 \mathrm{~F}$ e G). Nos cotilédones, já antes de se abrirem plenamente, verificam-se sulcos longitudinais e são plicados.

As plântulas, após cinco dias da germinação, já estão com a raiz principal medindo, em média, 2,5 cm de comprimento (Figura $2 \mathrm{G}$ ). Após doze dias, as raízes primárias atingem, em média, $6 \mathrm{~cm}$, e com 60 dias, $13 \mathrm{~cm}$ (Figura 2-I). Noventa dias após a germinação, as plantas podem alcançar $18 \mathrm{~cm}$ de altura. As folhas cotiledonares tornam-se fotossintetizantes logo que emergem do pirênio. Em cerca de três dias expandem-se e em cinco dias atingem seu tamanho definitivo, de contorno arredondado, margem ligeiramente dentada e são conspicuamente plicadas. As raízes secundárias aparecem entre o quinto e o oitavo dia, continuando a surgir novas raízes subseqüentemente. A zona de delimitação entre o hipocótilo e a raiz é notada com cerca de quatro dias de germinação. O hipocótilo é verde-claro, de desenvolvimento rápido, alongandose mais do que a raiz primária nos primeiros dias. Subsequentemente, a raiz primária torna-se mais desenvolvida. Entre o décimo quinto e o vigésimo dia, 
os primórdios foliares tornam-se visíveis e o epicótilo desenvolve-se surgindo os primeiros eófilos, simples alternos, ovalados, e de margem ligeiramente dentada, com venação bronquidodroma (Figura 2 I) e com 2,4 $\mathrm{cm}$. Com aproximadamente 60 dias, as plantas jovens possuem epicótilo com cerca de $5,0 \mathrm{~cm}$ de comprimento e 6-10 eófilos, alternos, e com características semelhantes às anteriormente descritas. O sistema radicular é bem desenvolvido, com raiz principal medindo cerca de $12 \mathrm{~cm}$ de comprimento com muitas ramificações. As folhas cotiledonares permanecem na planta até cerca da 120 dias, quando ocorrem sinais de senescência e caem.

Foram obtidos $93 \%$ de germinação.

\section{Cordia myxa}

\section{Morfologia da unidade de dispersão}

Frutos maduros globosos, simétricos e com vestígios do estilete no ápice em ligeira reentrância, e quando maduros, a coloração varia de amarelo-pálido a alaranjada. São providos de exocarpo membranáceo, mesocarpo suculento e mucilaginoso e endocarpo pétreo. Cálice persistente, glabro de coloração verde (Figura 3 A, B e C) que permanece aderido ao fruto durante todo o seu desenvolvimento e nos frutos menores notam-se vestígios do estilete e da corola. As figuras $1 \mathrm{~A} 1, \mathrm{~B} 1 \mathrm{e}$ $\mathrm{C} 1$ representam seç̧ões longitudinais de frutos em diversos estágios de desenvolvimento, ao passo que as figuras 1 A2, B2 e C2 correspondem a secções transversais. Pirênio elíptico, com duas reentrâncias, uma em cada pólo (Figuras 4 A e C); superfície de coloração brancacenta e nitidamente rugosa. Cortes transversais do fruto em diferentes estágios do desenvolvimento (Figuras 1 A2, B2 e C2) revelam a presença inicial de quatro lóculos (Figura 1 A2) que, por aborto, resultam em um único lóculo, raramente dois, no interior do qual se desenvolve uma semente. Os cortes longitudinais revelam uma protuberância no ápice do fruto que corresponde ao ponto de inserção do estilete com os estigmas. Em frutos mais desenvolvidos, notase o eixo hipocótilo-radícula do embrião voltado para a micrópila, o que parece estar relacionado com a protuberância anteriormente mencionada (Figura 1 C1). Frutos de C. myxa maduros com diâmetro médio de 1,43 $+0,06 \mathrm{~cm}$ (média + desvio-padrão), variando entre 1,63 $\mathrm{cm}$ e 2,34 cm. A massa fresca revelou a média de 1,80+ 1,32 g (média + desvio-padrão) variando de 1,04 a 2,54 g.

\section{Aspectos da germinação}

O início da germinação de C. myxa ocorre após 20 a 40 dias, com a emergência da raiz primária (Figura 4 B). A germinação é fanerocotiledonar epígea e inicia-se com a emissão da raiz rompendo e liberando-se do endocarpo por um opérculo (Figuras 4 B e C) em uma de suas superfícies abauladas, expondo parte do tegumento. Três dias após a protrusão da raiz, inicia-se a saída dos cotilédones. Antes de os cotilédones se abrirem plenamente, observam-se sulcos longitudinais (Figuras 4 D, E e F). As folhas cotiledonares, ainda parcialmente dentro do endocarpo, são plicadas e de coloração verde-clara (Figura 4 D). Depois de cinco dias, liberam-se do endocarpo (Figuras $4 \mathrm{E}$ e F) e com aproximadamente oito dias alcançam seu tamanho definitivo. Cotilédones foliáceos, arredondados e com venação trinervada. Em algumas plântulas, constata-se o endocarpo preso ao cotilédone e, pode-se observar o tegumento da semente como mostra a Figura 4 D. A raiz primária desenvolve-se rapidamente e em três dias atinge $2 \mathrm{~cm}$ de comprimento (Figura $4 \mathrm{D}$ ), já ocorrendo diferenciação entre hipocótilo e radícula. O hipocótilo possui coloração verde-clara e alongase mais rapidamente do que a raiz primária no início. Nas figuras 4 A, B e C observam-se diversos estágios do início da germinação.
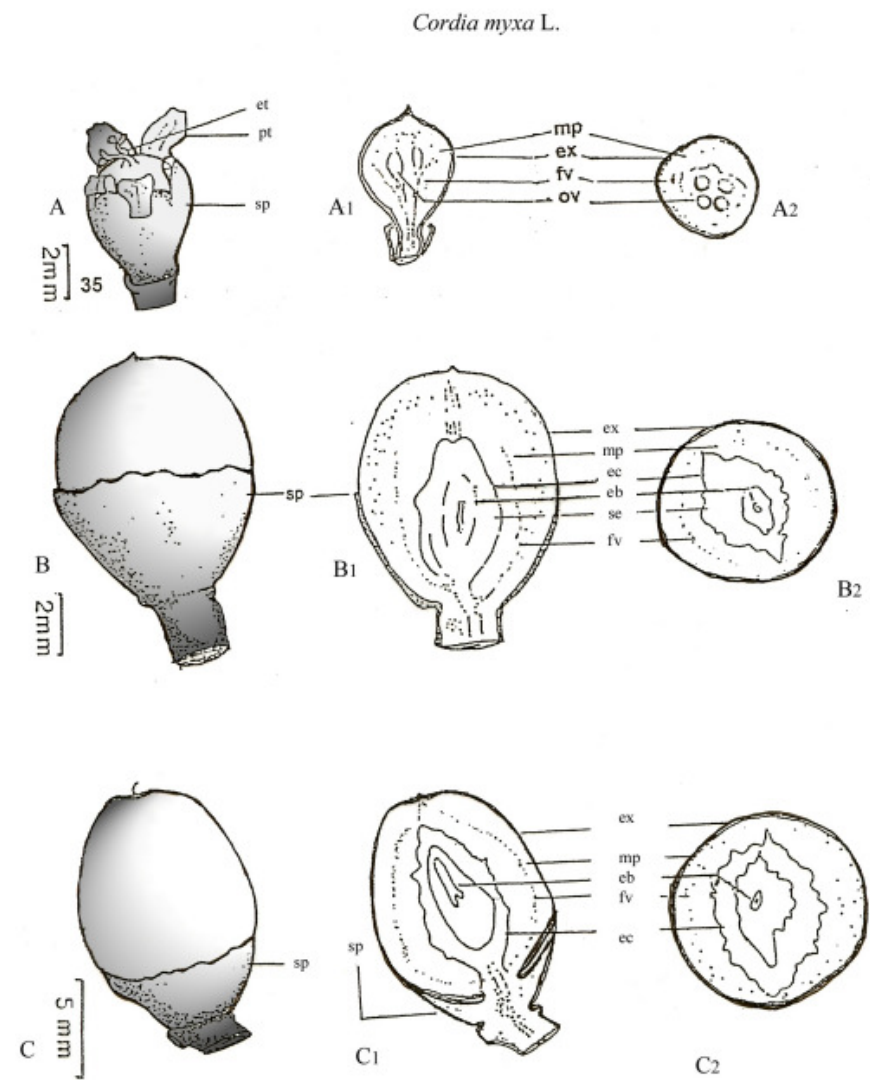

Figura 3. Cordia myxa L. A, B e C: frutos inteiros; A1, B1 e $\mathrm{C} 1$ = frutos cortados longitudinalmente; $\mathrm{A} 2$, B2 e C2 $=$ frutos cortados transversalmente. Ex = exocarpo; $\mathrm{mp}$ = mesocarpo; ec = endocarpo; $\mathrm{se}=$ semente; $\mathrm{eb}=$ embrião; fv = feixe vascular; ov = óvulo. 


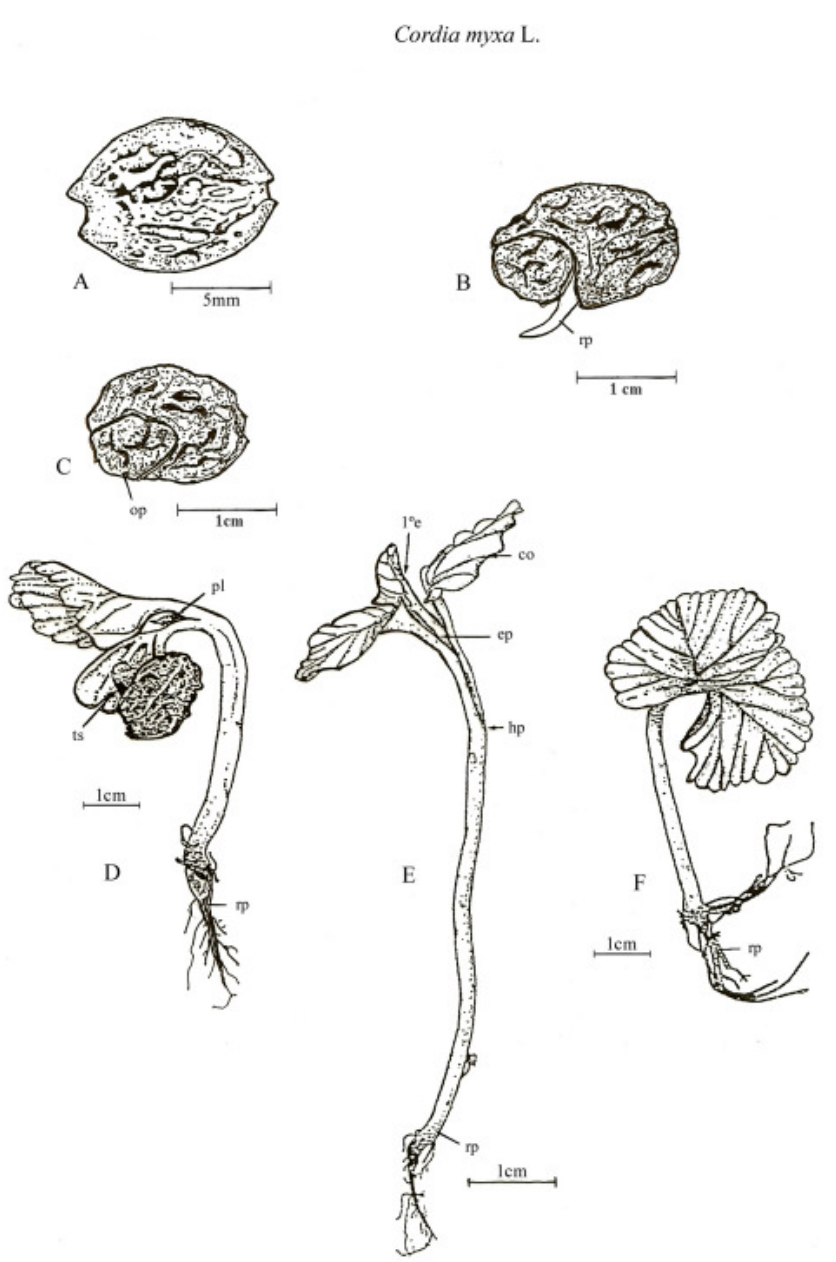

Figura 4. Cordia myxa L. A = pirênio em fase estacionária; $\mathrm{B}$ e $\mathrm{C}=$ pirênio em germinação; $\mathrm{D}$ e $\mathrm{F}=$ plântulas; $\mathrm{E}=$ planta jovem; ts = tegumento da semente; op = opérculo; $\mathrm{rp}=$ raiz primária; $\mathrm{ep}=$ epicótilo; $\mathrm{hp}=$ hipocótilo; $c o=$ cotilédones; $\mathrm{pl}=$ plúmula; $1^{\circ} \mathrm{e}=$ primeiro eófilo.

O endocarpo pétreo, com a semente em estágio estacionário em seu interior, é de coloração castanhobrancacenta, superfície irregularmente abaulada com protuberâncias e duas reentrâncias, uma em cada pólo, sendo uma menor, indicando o local de inserção do pedicelo e outra um pouco maior (Figura $4 \mathrm{~A}$ ). Ao emergir do endocarpo, a raiz primária é branca e curva. A plântula com oito dias possui raiz primária em torno de $4,5 \mathrm{~cm}$ de comprimento e raízes secundárias. Com dez dias, possui 12,5 cm de comprimento, raiz primária brancacenta e hipocótilo esverdeado e cilíndrico.

Os cotilédones são foliáceos, membranáceos, pouco pilosos, opostos, plicados, de coloração verdeclara, com três nervuras principais (trinervado) com 4,0 $\mathrm{cm}$ de largura e 2,6 cm de comprimento. $O$ ápice caulinar mede 0,6 cm de comprimento e é verde-claro. Plântulas com quinze dias já atingem $14 \mathrm{~cm}$ de comprimento e o primeiro eófilo mede $1,2 \mathrm{~cm}$ de comprimento.
Nas condições experimentais foram obtidos $36 \%$ de germinação entre 20 - 30 dias; com 40 dias de semeadura obteve-se $56 \%$ de germinação.

Os frutos de Cordia L. são de tipos variáveis. Em Cordia trichotoma Vell. ex Steud. os frutos são secos. Cordia ecalyculata Vell possui frutos do tipo drupóides nuculânio, ou seja, fruto do tipo drupa, com um pirênio com mais de um lóculo (BARROso et al., 1999). Tanto nos frutos de C. sellowiana como nos de C. myxa observa-se o pirênio com mais de um lóculo constituindo frutos do tipo drupóide nuculânio.

Frutos de C. sellowiana contêm geralmente uma única semente, ao passo que os de C. myxa, uma ou duas sementes. Os frutos das duas espécies são globosos, glabros, amarelos quando maduros e ricos em mucilagens, o que justifica sua procura pelos pássaros e seu uso como expectorante na medicina popular. Os frutos de C. ecalyculata citados por SAITO (1984) são vermelhos quando maduros e igualmente mucilaginosos.

Segundo RAVEN et al. (2001), os frutos evoluíram por mecanismos diversos, envolvendo diferentes agentes dispersores, especialmente animais. Muitas plantas possuem diásporos que são transportados por mais de um agente e constituem exemplos de casos de policoria ou diplocoria (PIJL, 1982). Esse autor afirmou que a morfologia de frutos e sementes freqüentemente indicam o processo envolvido na dispersão e que cada agente dispersor pode agir em diferentes situações e não com a mesma intensidade.

ERCOLINI BARRoso (2002) menciona que a dispersão das espécies é feita por mamíferos de porte variado e por aves. Assim, observou maitacas (Pionus sp.) forrageando frutos de C. sellowiana. Em Rio Claro, foram observadas formigas alimentando-se de frutos das duas espécies.

O processo de dispersão das duas espécies carece ainda de estudos que permitam ampliar conhecimento.

Segundo Duke (1969) há dois tipos de germinação: a criptocotiledonar em monocotiledôneas e a fanerocotiledonar, mais comum em dicotiledôneas. Esse autor estudou espécies de Cordia cuja germinação fanerocotiledonar se caracterizava pelos cotilédones plicados e dentados. Em C. sellowiana e C. myxa também se observam essas características.

As sementes de C. myxa não germinaram quando seus frutos foram retirados da planta mãe e despolpados no instante em que estavam com coloração amarelo-alaranjada e o exocarpo 
e o mesocarpo, levemente amolecidos. Entretanto, germinaram na ordem de $56 \%$ entre 20 e 40 dias, quando foram retirados do solo debaixo da planta mãe.

Em C. sellowiana, nas condições do plantio, ocorrem $93 \%$ de germinação.

Tschinkel (1967) observou que sementes de Cordia alliodora (Ruiz e Pavan) Cham., coletados até seis semanas antes da disseminação natural não germinam. A germinação aumenta e atinge um valor máximo três semanas antes de sua queda natural.

Esse fato parece indicar que melhores estudos sobre a germinação tanto em espécies autóctones de Cordia, como C. alliodora, e de espécies exóticas como C. myxa sejam feitos. O método de coleta e a seleção de sementes levam a obter melhor qualidade fisiológica, isto é, sementes desenvolvidas sem defeitos, não predadas e coletadas em época apropriada (TsCHINKel, 1967; VIANNA, 1982). Observações cuidadosas sobre o desenvolvimento de sementes permitem determinar o ponto ótimo de maturação e melhores resultados na germinação (Stead, 1978 apud Vianna, 1982).

Muitos autores ressaltam que, além da unidade de dispersão, é imprescindível melhor conhecimento da germinação, do crescimento e do estabelecimento da plântula para a compreensão do ciclo biológico e da regeneração natural da espécie (Oliveira, 1993).

Pode-se observar que as duas espécies germinam sobre o folhedo, tanto dentro quanto um pouco acima do solo.

Existe na literatura certa confusão quanto aos nomes empregados para a descrição e classificação das plântulas. Essa não-uniformidade ocorre principalmente no que diz respeito à distinção abaixo do solo ou ao nível do solo e na escolha das características usadas na classificação (SORIANo e TORREs, 1995). Esses autores afirmaram ainda que esse tipo de classificação se torna artificial, pois a semeadura ocorre em condições controladas. A terminologia de Duke (1965) parece ser a mais usada.

ERCOLINi BARroso (2002), considerando as afirmações de BeLtrati (1978) salientou as dificuldades de se conceituar plântula reconhecendo que até o momento esse termo não foi definido de maneira precisa, sendo utilizado com diferentes significados por diversos autores. A autora emprega o nome de plântula até o aparecimento do primeiro eófilo e de fase juvenil para a etapa seguinte até o aparecimento do primeiro metáfilo.
A raiz primária emerge do pirênio através de uma fenda lateral em $C$. sellowiana e através da abertura de um opérculo em C. myxa. Inicialmente esbranquiçada e robusta em $C$. sellowiana e mais delgada em C. myxa, de crescimento relativamente rápido, com muitos pêlos absorventes observados a olho nu. Após algum tempo, essa raiz torna-se castanho-escura, quase negra em C. sellowiana, sendo pouco mais clara em C. myxa. A região do colo em $C$. sellowiana fica inflada. Fato semelhante ocorre em $C$. myxa. Hipocótilo de coloração esverdeada em ambas as espécies, em C. myxa com poucos tricomas longos e brancos e em $C$. sellowiana com muitos tricomas curtos e transparentes. Nas duas espécies, a região de transição entre a raiz primária e o hipocótilo fica bem evidente. Os cotilédones são arredondados folhosos, fotossintetizantes, opostos, curto peciolados, plicados e margens dentadas nas espécies estudadas.

Em C. myxa os cotilédones são verde-claros, glabros na superfície adaxial e com tricomas nas nervuras da face abaxial, a venação é trinérvea, e veias secundárias pouco conspícuas. C. sellowiana possui cotilédones verdeescuros pubescentes, plinérveos e de venação proeminentes em ambas as faces. DuKE (1965), Amo-Rodrigues (1979) e SORIANO e TORRES (1995) citam a presença dessas características em outras espécies de Cordia.

Muitos autores, tais como Duke e POlhill (1981) asseveram que o período mais crítico do ciclo de vida da maioria das espécies vegetais é o juvenil. Amo-Rodrigues (1979) comentou que esse período é pouco conhecido, embora a capacidade de reconhecimento das plântulas e dos estágios juvenis em um dado ecossistema possa ter valor no estudo da dinâmica de populações, podendo servir de índice para caracterizar o estágio sucessional em que o ecossistema se encontra.

Segundo Amo-Rodrigues (1979), a diferenciação dos estados jovens é difícil e problemática, porque as diferenças que se utilizam estão reduzidas às características das folhas e em alguns casos a caracteres distintos de caules. A caracterização das folhas em estágios juvenis é importante já que, em muitos casos, há diferenças entre as primeiras folhas (eófilos) e as adultas (metáfilos).

A transição entre as primeiras folhas e as folhas adultas, nas duas espécies, é tardia, pois, em $C$. myxa, ainda há eófilos aos oito meses e em C. sellowiana, aos 18 meses. Os eófilos possuem margem dentada e os metáfilos, margem inteira em ambas as espécies. DuKE (1969) descreveu a germinação de várias espécies de Cordia, entre elas C. ecalyculata, em que a margem dos eófilos é parcialmente serrada e inteira nos metáfilos. Em outras espécies de Cordia observou-se que os eófilos possuem margem variando entre dentada e serrada, ao passo que os metáfilos, são inteiras. 
Miquel (1987) afirmou que classificações mais detalhadas, que considerem um grande número de características, permitem visualizar os tipos de plântulas em uma perspectiva evolutiva. Comentou ainda que em estudos de comunidades constata-se que as sementes e as plântulas são fortemente influenciadas pelo ambiente, apesar das características filogenéticas da espécie estarem presentes.

\section{CONCLUSÕES}

1. Os frutos de C. sellowiana e C. myxa são do tipo drupóide nuculânio. Inicialmente são providos de quatro lóculos que no final do desenvolvimento se reduzem a um, contendo uma única semente. C. myxa pode originar dois lóculos e duas sementes.

2. Os frutos de C. sellowiana quando maduros são providos de exocarpo membranáceo, mesocarpo suculento e mucilaginoso e endocarpo pétreo; com diâmetro entre $1,40 \mathrm{~cm}$ e $2,02 \mathrm{~cm}$ e massa fresca de $3,90 \mathrm{~g}$.

3. Os frutos de C. myxa quando maduros são providos de exocarpo membranáceo suculento e mucilaginoso e endocarpo pétreo; com diâmetro entre $1,63 \mathrm{~cm}$ e $2,34 \mathrm{~cm}$ e massa fresca de $1,04 \mathrm{~g}$ a $2,54 \mathrm{~g}$.

4. O tipo de germinação das duas espécies é fanerocotiledonar epígea e os embriões possuem cotilédones plicados e margens dentadas. As sementes de C. myxa não germinam quando seus frutos são colhidos da planta mãe e despolpados quando estão com a coloração alaranjada e o exocarpo e o mesocarpo amolecidos; entretanto, germinam na ordem de $56 \%$ entre 20 e 40 dias, quando coletados no solo debaixo da planta mãe. As sementes de C. sellowiana, nas condições do plantio, atingem $93 \%$ de germinação entre 18 e 32 dias.

5. O processo de germinação de C. sellowiana é caracterizado pelo intumescimento do pirênio e subseqüente rompimento da parede, com ocorrência de fenda longitudinal e protrusão da raiz primária. A germinação de C. myxa se inicia pela protrusão da raiz primária, liberando um opérculo de contorno variando de obtuso retangular a arredondado.

6. Em C. myxa as plântulas com 15 a 20 dias atingem, em média, $14 \mathrm{~cm}$ de comprimento e o primeiro eófilo mede cerca de $1,2 \mathrm{~cm}$; em $C$. sellowiana as plântulas medem cerca de $16 \mathrm{~cm}$ de comprimento e o primeiro eófilo alcança $2,4 \mathrm{~cm}$ de comprimento.

7. A transição entre as primeiras folhas e as folhas adultas nas duas espécies é tardia. Em C. myxa ainda se observam eófilos aos oito meses e $C$. sellowiana, aos 18 meses.

\section{REFERÊNCIAS}

AMO-RODRIGUES, S. Clave para plântulas y estados juveniles de espécies primárias de uma selva alta perenifólia em Veracruz. Biótica, Ciudad de México, v.4, n.2, p.59-108, 1979.

BARROSO, G.M.; AMORIM, M.P.; PEIXOTO, A.L.; ICHASO, C.L.F. Frutos e sementes: morfologia aplicada à sistemática de dicotiledôneas. Viçosa: Editora UFV, 1999. 443p.

BELTRATI, C.M. Morfologia e anatomia de sementes e plântulas de Eucalyptus modenii. Turrialba, San José, Costa Rica, v.28, n.3, p.208-215, 1978.

BELTRATI, C.M. Morfologia e anatomia de sementes. Rio Claro: Departamento de Botânica, UNESP, 1994. p.108. (Apostila do Curso de Pós-Graduação).

BOELKE, O. Estúdio de las semillas de Leguminosas Mimosóideas y Caesalpinoideas de interés agronomico en la Argentina. Darwiniana, Buenos Aires, v.7, n.1, p.240-312, 1946.

BRANDÃO, M.G.L.; CONSENZA, G.P.; MOREIRA, R.A.; MONTE-MOR, R.L.M. Medical plants and other botanical products from the Brazilian official pharmacopeia. Revista Brasileira de Farmacognosia, João Pessoa, v.16, n.3, p.408-420, 2006.

BRAVATO, L.D. Estúdio morfológico de las semilas de las Mimosoideae (Leguminose) de Venezuela. Acta Botánica Venezuelana, Caracas, v.9, p.317-361, 1974.

BRITTON, D.M. Citognetic studies on the Boraginaceae. Brittonia, New York, v.7, n.4, p.233-266, 1951.

CORREA, A.P.R.; RODRIGUES, A.G.; BARBANO, D.B.A. Política nacional de plantas medicinais e fitoterápicos. Brasília, DF: Ministério da Saúde, 2006. 60p. (Textos Básicos de Saúde Série B)

DUKE, J.A. Keys for identification of seedling of some prominent woody species in eight forest types in Puerto Rico. Annal of the Missouri Botanical Garden, Missouri, v.52, n.3, p.314-50, 1965.

DUKE, J.A. On tropical seedlings, systems and systematics. Annal of the Missouri Botanical Garden, Missouri, v.56, n.2, p.125-161, 1969.

DUKE, J.A.; POLHILL, R.M. Seedlings of Leguminosae. In POLHILL, R.M.; RAVEN, P.H. (Ed.). Advances in legumes systematic. Royal Botanic Gardens: Kew, 1981. v.2, n.2, p.941949. [Crown Copyright]

ERCOLINI BARROSO, I.C. Morfoanatomia da raiz, caule, folhas frutos e desenvolvimento de plântulas de Cordia sellowiana Cham. e de Cordia myxa L. Boraginaceae Jussieu. 2002. 151f. Dissertação (Mestrado em Biologia Vegetal) Instituto de Biociências, UNESP, Rio Claro.

LORENZI, H. Árvores brasileiras: manual de identificação e cultivo de plantas arbóreas nativas do Brasil. Nova Odessa: Instituto Plantarum de Estudos da Flora Ltda., 1992. 351p. 
MIQUEL, S. Morphologia functionale de plantules d'espécies forestières du Gabon. Bulletin du Museum National d'Hìstoirè Naturelle, Paris, v.9, p.101-121, 1987.

MURLEY, M.R. Distribution of Euphorbiaceae in Iowa, with seed keys. Iowa State College Journal of Science, Iowa State College, v.19, n.4, p. 415-419, 1945.

PIJL, L. Van der. Principles of dispersal in higher plants. 3 ed. Berlin: Springer Verlag, 1982. 241 p.

OLIVEIRA, E. de C. Morfologia de plântulas. In: AGUIAR, I. B. de; PIÑA-RODRIGUES, F. C. M.; FIGLIOLIA, M. B. Sementes Florestais Tropicais. Brasília: ABRATES, 1993. p.175-502.

PALÁCIOS, R.A.; BRAVO, L.D. Estudio morfológico de las semilhas de Prosopis II: algumas especies norte americanas y neotropicales. Darwiniana, San Isidro, v.19, n.2-4, p.357-372, 1975.

RAVEN, P.H.; HOPKINS, M.J.G.; VICENTINI, B.; SOUZA, J.M. Biologia vegetal. Rio de Janeiro: Guanabara Koogan, 2001. 906p.

RICARDI, M.; HERNANDEZ, C.; TORRE, F.M. Morfologia de plântulas de arboles de los bosques del Estado Mérida. Mérida, Venezuela: Talleres Gráficos Universitarios, 1987. 423p.

SAITO, M.L. Farmacognosia de Cordia ecalyculata Vell. (Boraginaceae). 1984. 154f. Dissertação (Mestrado em Fármaco e Medicamentos) - Universidade de São Paulo, São Paulo.

SORIANO, S.; TORRES, R.B. Descrição de plântulas de árvores nativas. In: Congresso da Sociedade Botânica de São Paulo. Anais. São Paulo: Sociedade Botânica de São Paulo, p.27-46. 1995

SPUJT, R.A. A systematic treatment of fruits types. Memories of the New York Botanical Garden, New York, v.70, p.1-72, 1994.

TSCHINKEL, H. La madurez y el almacenamiento de semillas de Cordia alliadora (Ruiz \& Pavon) Cham. Turrialba, San José, v.17, n.1, p.89-90, 1967.

VIANNA, N.G. Produção e tecnologia de sementes de freijó (Cordia goeldiana Huber). Belém: Embrapa-Cpatu, 1982, 37p. (Circular Técnica) 